\title{
Monsters in Law: una lectura de Ester, de Jean Racine
}

\author{
Monsters in Law: A Reading of Esther, by Jean Racine
}

Joaquín TRUJILLO SILVA 1

Universidad de Santiago de Chile joaquintrujillosilva@gmail.com

\section{Resumen}

El ensayo revisa en los diálogos-no-filosóficos la aparición de los monstruos en contextos normativos (moral en Racine; social en Ibsen y político en Brecht) (secciones 1, 2, 3). En su sección principal (4), explora cómo es que en la "tragedia" Esther, de Jean Racine, el monstruo aparece al menos como soberano y como consejero del soberano. Concluye que, a través de su propuesta de diálogo, Jean Racine intenta influir sobre el soberano mediante su segunda esposa, tal como Mardoqueo lo había hecho a través de la reina Ester, en el libro del Tanaj hebreo.

Palabras clave: Monstruo; derecho; ley; soberanía; consejero; doctrina.

\begin{abstract}
The essay reviews, with non-philosophical dialogues, the appearance of monsters in normative contexts (moral in Racine; social in Ibsen and political in Brecht) (sections $1,2,3)$. In its main section (4), it explores how it is that in Jean Racine's "tragedy" Esther, the monster appears at least as a sovereign and as an advisor to the sovereign. It concludes that, through his proposal for dialogue, Jean Racine tries to influence the sovereign through his second wife, just as Mordecai had done through Queen Esther, in the Tanakh.
\end{abstract}

Keywords: Monster; right; law; sovereignty; counsellor; jurisprudence.

\footnotetext{
1 Abogado (U. de Chile), magíster en Estudios Latinoamericanos (U. de Chile), Dr. (c) en Literatura (U. de Chile). Investigador CEP y profesor de la Universidad de Santiago de Chile y de Chile (invitado). Autor de la novela Lobelia (Ril, 2017) y Andrés Bello: libertad, imperio, estilo (Roneo, 2019), además de teatro y poesía.
} 


\section{Introducción}

Tras un prolongado silencio que ha sido considerado un "gran misterio de su carrera" (Greenberg 2010: 226), el poeta cortesano Jean Racine (1639-1699) accedió al encargo de Madame de Maintenon (1635-1719) —en ese entonces cónyuge morganática de Luis XIV (1638-1715) - para que escribiese un drama. Racine

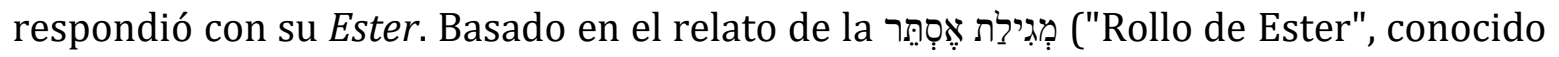
también simplemente como Meguilá) contenido en el Tanaj hebreo (Antiguo Testamento cristiano), el drama escrito por Racine mostraba las decisiones que debía tomar una reina consorte de recambio para salvar a su pueblo del exterminio. Esas decisiones la ponían en peligro y le significaban concluir exitosamente una intriga cortesana contra Amán, un monstruo que se había convertido en consejero áulico del monarca de Media y Persia, el rey Asuero. La pieza de Racine fue representada por las niñas de un colegio hasta que, molesta por los hombres que concurrían para admirar a las aficionadas, Maintenon clausuró las funciones.

El caso es de tanto provecho por la estrategia de domesticación en el que se enmarca. Luis XIV fue el monarca famoso por doblegar a los nobles provinciales sometiéndolos a su órbita (sin ir más lejos, tal como Versailles congregaba nobles provinciales, el establecimiento educacional de Saint-Cyr reunía a niñas de todo el país). Como se sabe, Luis XIV fue conocido como "el rey sol”. Por su parte, el sol dentro del sol fue Madame de Maintenon.

Pues bien, el derecho ha sido descrito como una gran faena de domesticación. Forma pacífica de solución de controversias, el derecho difícilmente no tenga algo de eso, pero también, su capacidad de domesticar no depende exclusivamente de él mismo. La idea de que el derecho exista por fuera, a pesar de o contra la fuerza bruta, o su figuración simbólica, el monstruo, hace preguntarse cuál sea la dinámica entre el derecho y los monstruos.

El estudio de los diálogos-no-filosóficos antiguos y modernos es, para dichos efectos, una fuente inagotable. El teatro no es solamente representación escénica: es, en sus apariciones clásicas, una forma especial del diálogo-no-filosófico (quiero insistir con esta fórmula) que comenta y acaso glosa las acciones acontecidas fuera de la escena, grupo al cual pertenece el aspecto forense y litigioso del derecho. Es el caso de todos aquellos diálogos del teatro clásico y neoclásico ajustados a las reglas de unidad de tiempo y lugar, y que obviamente Shakespeare y muchos otros pasaron por alto, contaminando de fuerza bruta las escenas dialógicas, hasta entonces más o menos impolutas, de los comentarios y glosas: como si un tribunal tuviese por fuerza que admirar el delito cara a cara.

La cuestión más bien teórica respecto de por qué el derecho y el texto dramático serían formas del diálogo-no-filosófico es una cuestión que hemos tratado en otro lado (Trujillo, 2022). Con este ensayo, en cambio, me ocuparé de algo menos 
pretencioso, cual es el tratamiento de los monstruos al interior - y a la intemperiede tres autores insoslayables: Jean Racine, Henrik Ibsen y Bertolt Brecht. En realidad, esta triada no es más que un pretexto obligado para referirme al que verdaderamente me importa: Jean Racine, en quien encontramos el estado más puro de ese diálogono-filosófico sobre el razonamiento práctico. Si Blaise Pascal hubiese redactado sus fórmulas en forma de diálogos, Jean Racine hubiese sido Pascal.

Tras pasar por los tres, veremos al final cómo es que el drama de Ester adquiere un sentido especial.

Un caso moral (Fedra), uno social (Casa de muñecas) y otro político (La resistible ascensión de Arturo Ui) es lo que encontramos en las piezas de Racine, Ibsen y Brecht, respectivamente, que aquí comento. Sin embargo, estas distintas apariciones de monstruo moral, social y político tienen en el caso de la Ester, de Jean Racine, una suerte de caso perfecto para observar cómo esa tensión de literatura y derecho (o sea, de estilo y precepto) que, en buena parte, es la crónica histórica, será retóricamente conducida para la consecución de dos fines propiamente jurídicos: la represión de un monstruo y la limitación de otro que parecía serlo.

Es ese, por lo tanto, el itinerario de este ensayo.

\section{1}

Fedra (cuyo estreno data de 1677) ha sido considerada la tragedia de las pasiones atrapadas, la de los rostros sonrojados, con un desenlace que es un estallido de muerte. Por lo mismo se la ha tenido por una exhibición sádica de vergüenza ajena. Todavía hoy la despierta. No por nada, en su notable ensayo de 1963 Sur Racine, Roland Barthes la llamó: "tragedia de la palabra escondida, de la vida retenida". Pero hay en esta tragedia un telón de fondo jurídico-político que no es solo de fondo y que, si se mira con detenimiento, dirige el desarrollo de los eventos.

Este asunto ya se halla latente en la lectura que Virgilio o Dante hicieron del mito de Fedra. A diferencia de Virgilio que la encuentra entre los lujuriosos del infierno (Eneida VI, 445), Dante no la vio ahí en su lugar equivalente de la Divina Comedia sino que simplemente la menciona como una calumniadora (Paraíso XVII, 47). El hecho de que esa calumnia haya sido asimilada, por los especialistas en Dante, a una calumnia política - la sufrida por el propio Dante, que vivió exiliado de su natal Florencia a consecuencia de la misma - despliega una insoslayable posibilidad de lectura política (también Virgilio se refiere en Eneída VII, 761-780 al inocente forzado al exilio), que es la que intentamos explorar aquí (Padoan, 1970).

Pensada como una versión contemporánea - contemporánea para entonces: mediados del siglo XVII — de la tragedia más antigua Hipólito, de Eurípides (428 a.C.), la versión de Racine llegó a constituirse en la meta-traducción más autorizada de su 
antecesora y, por supuesto, en su mejora² (Bello, 1981-1987 [t.9]: 366), por sobre la versión romana (56 d.C.) del dramaturgo y filósofo Séneca, muy conocido como tutor de Nerón.

El problema político, sin embargo, puede ser mejor entendido como uno de ius publicum $\mathrm{y}$, a su vez, este último como uno acerca de la esencia misma del funcionamiento del derecho. En rigor, el asunto político es el siguiente: Teseo es el rey de Atenas, pero su reinado ha destronado a una casa real anterior, la de los Pallas, cuya última representante es Aricia (sus seis hermanos, pretendientes al trono, han sido exiliados por Teseo). A eso se agrega que dentro de la línea de sucesión dinástica de Teseo existe también una tensión: él tiene hijos; el primero es Hipólito (con la amazona Hipólita); otros dos, Acamante y Demofonte, con Fedra, su segunda y actual esposa (hija, a su vez, del rey Minos de Creta y reina consorte de Atenas).

Hasta antes de la supuesta desaparición de Teseo, Fedra ha reprimido su inconfesable amor por su hijastro Hipólito "siéndole nociva", pero la máscara en público, que es esta hostilidad, es también una trama política: como hijo mayor de Teseo, Hipólito es por fuerza el rival del hijo de Fedra en su titularidad de alternativo sucesor al trono. Fedra tiene a su favor el hecho de que, como hijo de una extranjera — la amazona Hipólita-, Hipólito no goza de aceptación popular.

Pero el problema es todavía más complejo. Hay en Hipólito un amor también inconfesable que se enmascara públicamente en su supuesta adhesión a Teseo en la rivalidad de éste con la dinastía de los Pallas. Eso "inconfesable” es el amor de Hipólito por Aricia. El problema político es que si Hipólito llegase a suceder a Teseo, y convirtiese a Aricia en reina consorte, se estaría restaurando, de cierta manera, la vieja dinastía destronada.

El verdadero hecho político de esta arcaica Atenas es que al morir Teseo la ciudad tendrá que definirse: o por Hipólìto, que es el mayor, pero hibrido y traidor de su padre si desposase a Aricia, o Acamante o Demofonte, que son segundos, no híbridos pero sí vástagos de una desmesurada que ha sido capaz de confesar su pasión por su propio hijastro, quien cuenta con esta sensible información a su favor.

Sin embargo, existe una tercera opción, una que circula por fuera de esta doble trama, y es que Aricia misma cuenta con partidarios que quisieran restaurar proclamándola a ella - la depuesta dinastía.

De ahí que, mientras Teseo se halla presente en Atenas, esta cuestión política parece inerte, pero cuando se lo cree muerto lejos de su reino, dicha cuestión se reaviva cual un fuego solapado.

\footnotetext{
2 Andrés Bello en su Compendio de la historia de la literatura, defendió las versiones de Jean Racine, y las versiones en general, de las tragedias griegas. En aquel libro, retóricamente, se pregunta: "¿Cuánto no debió Racine a Eurípides? ¿Y será degradado por eso el autor de la Ifigenia y la Fedra al rango oscuro de los imitadores y los copistas?" (Bello, 1981-1987 [t. 9]: 366).
} 
Como en varias tragedias y dramas históricos de Shakespeare, el problema de Teseo es el de la consolidación de su poder en la sucesión. Este problema, que Teseo acaso sabe gobernar sin aparentes fisuras, se desata cuando se cree muerto al rey, a consecuencia de lo cual ceden varias máscaras, entre ellas la de Fedra, la de Hipólito y la de Aricia.

Lo que pareciera nada más que una tensión al nivel de la casa real tiene otras derivas que no dejan de remecer el argumento y que hasta cierto punto empujan su desenlace.

Enone, Ismene y Terámenes — respectivamente la nodriza de Fedra, la confidente de Aricia y el mayordomo de Hipólito- son todos, en menor o mayor grado, informantes, confidentes, consejeros e instigadores. Por otra parte, y de alguna manera, a falta de un coro, hacen las veces de tal, asumen la presencia del pueblo cuya opinión suelen transmitir como si fuesen voceros o intuitivos especialistas en opinión pública. Terámenes anuncia la muerte de Teseo a Hipólito, como Enone a Fedra e Ismene a Aricia; aconsejan un cambio de planes con fines políticos: Terámenes aconseja a Hipólito salir de viaje y después quedarse para asumir el trono que ha dejado vacante su padre; Ismene, ablanda las desconfianzas de Aricia por Hipólito y le hace ver la oportunidad que le abre la muerte de Teseo; Enone, finalmente, es de los tres el más complejo: arranca la confesión a Fedra, le anuncia que con la muerte de Teseo su "crimen" se ha transformado en un hecho perfectamente "normal" (1.3), 3 la anima a confesar su amor para resolver así la cuestión de la sucesión al trono, conciliando la suerte del hijo de Fedra con las pretensiones regias de Hipólito y, por último, lo más importante, ante el retorno inesperado de Teseo, urde el engaño según el cual ha sido Hipólito el que se ha declarado a Fedra y no ella a él. La astuta Enone aprovecha que no existen otros testigos de este episodio para invertir el crimen testificando a favor de Fedra y en contra de Hipólito ante el único juez, el rey Teseo, marido y padre.

Sin embargo, existe tras este telón uno más oculto pero que es el fundamental: el derecho es la forma que tiene el poder y, por lo tanto, en ausencia del poder el derecho ha perdido su forma y, con esto, ha dejado momentáneamente de existir en espera de su nueva forma. Con todo, por otra parte Enone proclama que el crimen de Fedra puede, tras la muerte de Teseo, hacerse normal, o sea, hacerse legal ante la ley de Atenas. Mientras pareciera que las leyes de Atenas referentes a la sucesión al trono se mantienen incólumes, esta otra legalidad es la que entra en crisis, no porque deje de haber ley, sino debido a una expectativa: cuál sea el estatuto aplicable. Es decir, la ausencia del soberano no significa para todos los casos la desaparición de toda ley.

\footnotetext{
3 Para citar los actos, escenas y líneas o versos sigo el sistema de referencia abreviada: (Número de acto.número de escena.número de línea o verso).
} 
En esta brecha abierta en el mar de la legalidad aparecen dos engendros: el amor y el monstruo (que tal vez sean lo mismo). Tanto el amor de Fedra por Hipólito como el de Hipólito por Aricia son amores escandalosos por hallarse fuera de la ley, pero que dependen en buena medida, más que de la ley misma, del poder de esa ley, o sea, de la figura regia de Teseo. Por otra parte, cuando Teseo es engañado por el testimonio de Enone que más tarde se revelará como falso, y maldice a su hijo Hipólito, la aparición del monstruo marino que acaba con la vida de aquel joven ofendido es el otro engendro. Este segundo monstruo, que ha estado hasta el momento sumergido en el océano, aparece como la manera de devolver la normalidad a Atenas a través de una segunda anormalidad. Pues, en el acto II, cuando Fedra confiese su amor a Hipólito, ella se entiende a sí misma, en sus propias palabras, como un monstro. Por lo tanto, dos monstruos se han aparecido ante Hipólito y lo han matado: el del secreto mejor guardado de Fedra y el que invoca su padre, oculto bajo las aguas. Ambos monstruos son apariciones del amor: uno el amor incestuoso de la madrastra, el otro el amor del padre decepcionado ante la supuesta traición de su hijo. Ambos monstruos también son las caras de una misma moneda. Lo que no se debió decir, y se dijo, lo dicen Fedra y Teseo, ambos a Hipólito. Ella le dice el amor, él le dice la maldición. En la primera el monstruo aparece por dentro, en la segunda, por fuera. La segunda anomalía no es capaz de someter a la primera. El problema es tal vez peor en virtud de lo siguiente: el poder legítimo ya no es capaz de juzgar, en el sentido de hacerse una idea precisa de la realidad y obrar en consecuencia. Primero se ha ausentado, luego, se ha malinformado y, por último, ha sobrerreaccionado ("Reyes, cuiden al ausente / Contra la lengua homicida" dirá el propio Racine en Ester 3.3.975-976). No es descabellado pensar que haya aquí tal vez otra tragedia del nuevo poder. El poder de Teseo no ha sido heredado por él, pero sí será heredable. De ahí que sus títulos sean factibles de un estudio peligroso: la cadena sucesoria es demasiado nueva; mientras que la tradición que significa Aricia late en paralelo. Si Teseo carga con esta precocidad, más todavía Fedra, que es la madre de su segundo hijo, no del primero. Y es muy alumbrador que precisamente veamos en ella el intersticio a través del cual se estropea la opción de Hipólito, hasta el punto que bien puede conjeturarse que lo que ha hecho Fedra, deliberadamente o no, es mejorar la opción de su hijo, o para decirlo de otra manera, la de los secundarios, la de los aún más nuevos, la de eso que Teseo era pero no lo suficiente. Esta posibilidad se refuerza cuando recordamos que ha sido el testimonio de una sirvienta (Enone) el determinante para condenar a un príncipe (Hipólito). Así, lo que parece haber detrás de Fedra es una rebelión permanente, desde Teseo mismo hasta Enone, pasando por Fedra, Hipólito, Ismene y Terámenes, de los altos y bajos subalternos. La excepción tal vez sea Aricia. Ella, que es el amor verdadero, la humildad, la debilidad, ha quedado fuera de juego, acaso porque monstruos son todos aquellos que emergen a su alrededor, algunos como tales y otros todavía bajo la apariencia del amor. Una especie de lastre político, que con su 
existencia le recuerda al orden de Teseo que es demasiado débil porque es más joven que él mismo.

En Las heráclidas, de Eurípides (circa 430/426 a.C.), Demofonte aparece como sucesor de su padre Teseo como rey de Atenas. Políticamente hablando, Fedra parece haber triunfado.

\section{2}

Casa de muñecas (1879), de Henrik Ibsen, puede ser leída a la luz de Fedra.

Para nuestros efectos especialísimos, es preciso decir que en este drama, Nora Helmer, la protagonista, ha tenido que en secreto conseguir un préstamo para solventar los gastos del viaje terapéutico de su marido Torvald Helmer. Tras muchas penurias económicas, el abogado Torvald, que ha ejercido libremente la profesión, logra un alto cargo en un banco. En su afán de limpiar la nómina, Torvald quiere finiquitar a Nils Krogstad, uno de los mandos medios del banco, reputado corrupto y padre soltero. El problema es que ha sido Nils quien ha prestado a Nora. Como, además, Nils sabe que el aval del pagaré que garantiza el préstamo contiene una firma falsa, la supuesta del ya fallecido padre de Nora, Nils la chantajea con exponerlo a Torvald si éste lo finiquita del banco. Cuando finalmente lo hace, Nils dirige una carta a Torvald en la que revela la existencia del préstamo y la falsificación de documento. Deja la carta en el buzón de los Helmer la cual permanece ahí hasta que una noche Torvald la abre y se entera de lo que Nora ha hecho. Repudia a Nora y le exige que deje de educar a sus hijos, la acusa de corrupción y le dice que ha destruido su honor público.

Kristine Linde, la viuda amiga de Nora, que ha venido a la ciudad para conseguir un empleo, y que lo ha obtenido en el banco, una vez Nils ha sido despedido, corresponde al viejo amor que él siente por ella. Tras sus mutuas declaraciones, ella lo convence para que retire la carta contra Nora. Como ya no puede abrirse el buzón, Nils escribe otra carta en la que devuelve el pagaré. Tras abrir la primera, Torvald, lleno de furia contra Nora, abre la segunda, descubre en ella el pagaré, lo destroza y lanza los restos al fuego de la chimenea. A continuación, eufórico, perdona a Nora. Ella, sin embargo, ya ha visto otra verdad. Su marido no ha podido entender su sacrificio y su reacción demuestra que no le importa más que sí mismo. Así que lo abandona. Al final de la pieza se escucha el portazo de Nora que se va de noche. George Steiner (1970) vio en este recurso uno de los más altos momentos del teatro moderno.

Tal como en la Fedra de Racine, la supuesta normalidad del reino, y en el caso de Casa de muñecas, del hogar, reposa en el secreto que guarda la mujer. La verdad que oculta Fedra mantiene las cosas en orden del mismo modo como la confesión que no hace Nora, nutre silentemente la paz de Torvald. Teseo y Torvald - curiosa identidad de iniciales - son supuestos soberanos en sus respectivos territorios, A 
poco andar, nos enteramos de que aquella soberanía depende de factores demasiado específicos. Ambas pueden mantenerse porque cuentan con una realidad que está aprisionada. En términos de Ibsen, estas dos mujeres serían las columnas de la sociedad, pero quienes gobiernan la sociedad no lo saben ni parecen querer enterarse. La diferencia está en que mientras la serenidad del reino de Teseo descansa sobre una inacción silenciosa, la de Torvald, sobre una acción silenciada.

Ahora bien, existe en ambas obras una segunda línea de fortificación. Recordemos que es Enone la que convence a Fedra de confesar su amor escandaloso por Hipólito. Recordemos, además, que es Kristine Linde, la amiga de Nora, la que, correspondiendo el amor de Nils, induce la devolución del pagaré. En el caso de Enone, su fortificación cede, en el caso de Kristine Linde, la fortificación cumple su función. Pero en ambos casos, se cumpla o no, las dos mujeres, ambos segundos roles, son determinantes en el desenlace de la trama. Una porque su acción la desenvuelve, la otra porque la envuelve.

En el caso de las protagonistas, Fedra y Nora, ellas incurren — según los términos de la normalidad masculina - en un rompimiento de formas. La primera porque confiesa lo inconfesable, y con ese solo hecho ya rompe un código de conducta, más allá de que su pasión sea en sí misma reprochable, y la segunda, porque al falsificar la firma de su padre en un pagaré ha llevado más allá de lo irregular su primer heroísmo (haber pedido un préstamo a escondidas de su marido, cuando la ley noruega no lo permitía). Ambas, por supuesto, con sus actos buscan hacerse proteger por la forma de la ley, Fedra, porque según los cálculos de su nodriza, al desposarse con su hijastro Hipólito dejaría sin efecto el pleito por la sucesión del trono, y Nora, porque al conseguir supuestamente el aval de su padre, volvía indiferente su primera falta, cual era, solicitar un préstamo sin autorización del miembro capaz de la unión matrimonial.

Al hacerlo, y enterarse sus respectivos cónyuges, o sea, Teseo y Torvald, a cuyas espaldas ha ocurrido todo, no solo han despertado la indignación de ellos, que podría considerarse meramente impetuosa, sino que además han desatado aspectos oscuros de la naturaleza y la sociedad. En el caso de Fedra, la maldición de Teseo a su hijo Hipólito, a quien cree el infractor, desata al monstro marino; en el caso de Casa de muñecas, el resentimiento de Nils, que Torvald creía bajo control, puede salirse con la suya a causa de la irregularidad de Nora. Ambos monstruos son también productos de la indignación de los cónyuges-soberanos: la maldición de Teseo, que invoca a Neptuno, y el terror social que acongoja a Torvald por lo que Nils pueda hacer con el pagaré (distinto de solo cobrarlo), sabiendo, como sabe, que este mantiene contacto con la prensa amarillista local.

La crítica que ambas piezas hacen a la normatividad es la siguiente: hasta qué punto la obstinación del mundo que es todo razonamiento práctico, toda institución, todo derecho, si es que tiene algún ánimo de corregir ese mundo, no descansa sobre 
la condición tortuosa, pero en exceso tortuosa, de uno de los miembros de ese mundo. Mundo que —y esto es lo fundamental— se ve, pero no se ve, está ahí, como uno más, tal vez bajo la engañosa apariencia de miembro privilegiado, cuando al mismo tiempo, es su miembro más exigido. Cuando Racine observa que "su crimen [el de Fedra] es más bien un castigo de los dioses que un acto de su voluntad" ("Prefacio" de Fedra), comenta Barthes: "Todo el esfuerzo de Fedra consiste en reparar su falta, es decir, absolver a Dios", dice que Fedra es un Atlas sobre cuyas espaldas descansa la creación, las columnas de la sociedad.

Lo que, para nuestros efectos, plantean estas dos piezas, podría resumirse en que el problema de la distribución de cargas, que toda sociedad implica, no es más que el comienzo del problema, el aspecto rawlsiano del mismo, y por lo tanto, el aspecto digno de una posible política pública de redistribución de cargas. Lo que enseguida plantean ambas piezas, que es lo que las hace parecerse más a tragedias que a dramas, es que no es posible saber desde afuera cuál de todas es la columna que soporta el edificio. Solamente puede saberse dentro de ella misma. Y entonces, solamente conocemos cuál era la columna principal, cuando la quitamos y comprobamos la insolvencia del resto del conjunto, si es que el punto de presión no se trasladó a otra.

\section{3}

Cuando la columna deja de cumplir su función la fuerza invertida en ella no desaparece. Esa fuerza, desatada y ociosa, puede ser un monstruo. "La fuerza que irrumpe fuera de la profundidad marina", como dice Barthes, es el monstruo. Otra vez, mientras en Fedra para que esa fuerza estuviera ocupada hizo falta un deber de no hacer, en Casa de muñecas, uno de hacer. Por eso, la lectura trágica de Ibsen parece sugerirnos que se haga o no tal o cual, la fuerza invertida acabará desbordándose, de lo que se desprende que el monstruo es en sí inevitable. Entonces, ¿qué papel pudiera caber al derecho, a esa obstinación del mundo, en esta tragedia? Parece que ninguno, pero tal vez alguno. El derecho es un momento entre una tragedia y otra, pero especialmente uno durante la tragedia. La diferencia está en que las primeras son las de los monstruos, la segunda, la del amor, sea cual fuere. Sabemos que, en el fondo marino, aquel amor también es un monstro, del modo como sabemos que lo que ocurre durante el derecho también es una tragedia, aun cuando no lo percibamos como tal. Es un poco lo que Walter Benjamín dice respecto de la excepción: el derecho mismo es la excepción, aunque no se note sino cuando se rompe.

Bertolt Brecht aludió, o se refirió muchas veces al derecho, especialmente al ordenamiento constitucional de Weimar. Piezas como El círculo de tiza caucasiano y la sección "En busca del derecho" de Terror y miseria del Tercer Reich son en este sentido las más representativas. Pero también hay otras. 
En La evitable ascensión de Arturo Ui (1941), la última pieza que aquí comentaremos, la Alemania de entre guerras ad portas de Hitler aparece situada en el Chicago de los gánsteres. Los mafiosos se toman la ciudad, "la justicia entra en coma" (prólogo) y el orden burgués será incapaz de impedir el triunfo de Arturo Ui. Sin embargo, su ascenso es, según el propio título, "evitable".

Pues bien, la tesis de Brecht es que el ordenamiento burgués —en su caso el de la Constitución de Weimar de 1919- no es idóneo para poner bajo control al monstruo. Hacía falta, para ello, una transformación que la sociedad burguesa será incapaz de admitir. De ahí que el derecho sea una falaz emanación social que solamente controla aquello que puede sometérsele. Para Brecht, la evitable ascensión del monstruo es la prueba de que el derecho burgués — digamos aquí con Scott Shapiro (2013) - o es pernicioso o es ocioso, que no es otra cosa que la paradoja de la autoridad: por un lado, y si es que puede, solamente somete empleando la fuerza, incluso contra el sentido común. Por el otro, sin importar si puede o no, ocurre lo que el sentido común indica que es lo que deba ocurrir, sin que en eso el derecho tenga arte ni parte. Sin embargo — dirá Brecht— la autoridad del derecho burgués está en cuestión porque con Hitler quedó demostrado que no puede, si es que no, peor aún, se sirve del monstruo para, poder no pudiendo, hacerse necesario.

La precisa sátira de Brecht (como comedia, harto alemana) es, según sus propias palabras, una "parábola" de lo que fue y lo que está por venir. La pieza se esfuerza en convencer de que Hitler no es una anomalía, que puede volver a darse, que no es "un simio" único e irrepetible. Antes bien, la obra termina proclamando que el mundo no está seguro porque la "perra que lo parió está otra vez en celo".

Si el monstruo ha sido parido por una "perra", entonces cabe preguntarse qué debe hacer esa "perra" — o qué debe hacerse con esa "perra"- para que no vuelva a parirlo. La idea de que la sociedad burguesa sea una "perra" supone la incapacidad de su liberalismo - eso que hace "perra" a la "perra"- para hacerse cargo del monstruo. Cuando tras la debacle de la bolsa de Nueva York en 1928 Gramsci observa, en sus Cuadernos de la cárcel, que es en el "claroscuro" de lo que no acaba de morir ni de nacer donde surgen los "monstruos" no dice otra cosa: la indefinición de la sociedad burguesa es ahora un peligro especialmente para ella misma. Lo que para la sociedad burguesa es irresistible, no lo es para el mundo que está recién nacido. El monstruo parido por la perra tiene todo por delante a partir del ocaso, poco y nada a partir del amanecer. El amor de ninguna "perra" es suficiente para apaciguar al monstruo. Al lado de Arturo Ui, Nils Krogstad, de Casa de muñecas, no es más que un corrupto minúsculo.

Recordemos que el rompimiento de lo que llamamos Modernidad significó prescindir de las justificaciones tradicionalistas de la soberanía. E incluso, admitir que ni la propia razón ilustrada era idónea. De ahí que la presencia desnuda de lo fáctico se haga insoportable y las preguntas exijan sinceridad a las respuestas. Es el caso de 
la polémica entre Hans Kelsen y Carl Schmitt entorno a los fundamentos del derecho y, por lo tanto, sobre la soberanía. Si es la soberanía - por no decir simplemente el poder a secas - la que funda el derecho, ¿con qué derecho el derecho pretende someterla? Y es que no hay derecho anterior al derecho. La civilización liberal se olvida de su monstruo al punto que lo confunde con "un hecho más allá del cual no podemos seguir preguntando", para decirlo con George Simmel citado por Hans Kelsen.

Siguiendo las metáforas de Thomas Hobbes - entre dos tipos de monstruos, Leviatán y Behemoth (tomados a su vez de Job 40: 10-19) — Neumann (1943) dirá que mientras el Estado liberal es un Leviatán —un poder que, oculto bajo el agua, resguarda la isla-, el Estado nazi es un Behemoth (un monstruo visible que diezma la superficie de la isla).

En términos del Arturo Ui de Brecht, la discusión filosófico-jurídica de la Alemania de entre guerras, al menos en lo que concierne a la disputatio entre Hans Kelsen y Carl Schmitt, puede quedar así: para someter al monstruo hemos creado otro monstruo. Con el paso del tiempo hemos preferido domesticar nuestro propio monstruo. El problema es que en la medida en que se hace manso nuestro monstruo ya no cumple su función y el viejo monstruo que intentamos someter está de vuelta. E incluso, pensándolo bien podría reemplazar al nuestro. De tal forma que las preguntas son las siguientes: ¿Quién cuida nuestra vida civilizada? ¿El monstruo que ya no lo es, pero que es nuestro, o el que sigue siendo monstruo, y que es ajeno?

\section{4}

Tras su Fedra, injustamente recibida, Racine entró en un prolongado silencio. En 1687, Madame de Maintenon le encargó una pieza breve que pudiera ser representada por las señoritas de St. Cyr. Racine escribió Ester, su trabajo más corto, que fue representada en 1689 por las alumnas de dicho establecimiento próximo a Versailles (unas 250 niñas pertenecientes a la nobleza venida a menos).

La Ester de Jean Racine no solamente incluye referencias al texto canónico hebreo sino además a la sección apócrifa que se conservó en griego.

En el relato bíblico, Mardoqueo, un judío que vive en Susa, capital del Imperio Persa, educa a la huérfana Ester, perteneciente a la tribu de Benjamín, hijo de Jacob. Cuando la reina Vasti niega atenciones al rey Asuero, éste la repudia y busca, como dice Mitchell Greenberg, una "new beauty", una nueva consorte (Greenberg, 2010: p. 228). De entre las doncellas que le reclutan, él elige a Ester. Convertida en su mujer, la joven judía se halla horrorizada en los salones de la idolatría (lo que equivalía en ese entonces a ser la principal de un harem), pero se hace a la idea de desempeñar su papel. Posteriormente, Mardoqueo se niega a prosternarse ante Aman, el gran visir, quien, furioso, planea la aniquilación de todos los judíos que habitan el Imperio, para lo cual convence al rey de instruir a todas las provincias del Imperio y programar un 
solo día para exterminar a "esta raza alienígena" como ironiza la Jewish Encyclopedia (Hirsch et al., 1901-1906). Enterado de los planes de Amán, Mardoqueo pone a Ester al tanto y la conmina a interceder ante Asuero. Desconociendo el grado de compromiso que el rey Asuero ha adquirido en la empresa genocida de Amán —un pogromo motivado por la envidia que la prosperidad de muchos judíos engendra en los locales (Lemosín Martal, 1983: pp. 17-18) - Ester se atreve a confesarle su identidad judía a Asuero y a solicitar su ayuda. Antes, Asuero se había enterado por la lectura de las crónicas de los méritos de Mardoqueo para malograr una conspiración de eunucos contra el rey. Pero gracias a la intervención de Ester Asuero cambia de parecer, manda colgar a Amán en la horca que éste había preparado para ejecutar a Mardoqueo, y el día señalado para exterminar a todos los judíos, estos son autorizados para matar a sus agresores. Eso sí, no los despojan de sus bienes. Asuero nunca revoca su primer decreto, sino que emite otro de contenido levemente distinto.

La mencionada Jewish Encyclopedia, publicada originalmente entre 1901-1906, señala que si bien fue incluido en la Septuaginta - la traducción del Tanaj al griego que hicieron los 72 sabios entre los siglos III a I a.C. - su canonicidad será discutida todavía en los siglos I y II. Informa, además, que los rabinos explicaban que el que Ester haya insistido en invitar a Amán al banquete en el cual hizo sus revelaciones al rey, habría tenido por propósito celar a este último, de suerte tal que si moría ella muriese también Amán. Adicionalmente, que habría sido un ángel el que empujó a Amán sobre el diván para que Asuero creyese que Amán intentaba ultrajar a la reina y no simplemente arrodillarse. Agrega, asimismo, varias teorías dignas de mención como la de los eruditos Jensen y Nöldeke según la cual el relato se trataría de un mito babilónico-elamita en el que se enfrenta la diosa babilónica Ishtar o Afrodita (Ester) y el dios Marduk (Mardoqueo) contra el dios elemita Hamman o Humman (Amán) y la diosa Vasti, también elemita (Hirsch et al., 1901-1906).

Sin embargo, el libro de Ester subsistió entre los llamados protocanónicos de suerte tal que, a diferencia de otros de la Septuaginta, no fue arrancado por considerársele apócrifo. Es más, Moisés ben Maimón, más conocido como Maimónides (1138-1204), lo consideró indestructible por "tan eterno como la Torá" (Lemosin Martal, 1983: 9). Era, por lo tanto, en el siglo XVII, cuando Racine escribió su versión para el teatro de señoritas, un libro cuya canonicidad no era discutida por católicos y protestantes, así que sus guerras civicointernacionales —de 1562-1598, en Francia, y 1618-1648, en el Sacro Imperio - retenían otros pretextos.

Pero entremos ahora en el análisis de la pieza.

Ya en los versos de La Piedad, en el "Prólogo", percibimos la intención directamente política de esta Ester. En ellos Racine alaba a su benefactor, o tal vez su benefactora: "Y desafiando del demonio el impotente artificio, de la religión sostiene todo el edificio" (Pró.39-40). El discurso de La Piedad es doble. Al menos en apariencia, mientras por un lado concurre al flanco del Rin, contra el que se agolpan los enemigos 
de Luis XIV, por el otro, busca domesticar al enemigo interno. Lucha contra "el demonio" de afuera y el de dentro. Y claro, el caso de Ester es paradigmático. La reina no es reina de su propio pueblo, sino que de otro. Sobre Ester se sostiene esta tensión: ella protege a los suyos no siendo, también al menos en apariencia, uno de los ellos. Esta fórmula entra en crisis cuando Amán, que es descrito como el favorito del rey, se empecina contra los judíos del Imperio Persa. Entonces, y solo entonces, ella se ve obligada a revelar quién en realidad es. A diferencia de Fedra, la revelación de Ester, que tiene primordialmente un objetivo político, mejora su posición, y es por eso que la lucha de Ester contra los demonios que la acosan a ella y a su desprotegido pueblo, no es una tragedia. Más bien es una comedia de aciertos ${ }^{4}$ - como lo son también los deuterocanónicos o derechamente apócrifos Tobit y Judit-, que es lo que el derecho busca ser, las columnas visibles de la sociedad. Precisamente, por el hecho de que son visibles, esas columnas son factibles de un comentario fructífero.

El derecho es consorte de la política. Ella a veces lo defiende de los monstruos que vienen a través suyo, él a veces la defiende, también. Desde que en el diálogo-nofilosófico Sófocles incorporó al tercero, estos diálogos de a dos han pecado de simplicidad. El monstruo, sea el bravío o el domesticado, ronda los recintos del poder:

Sí, son, querido amigo, monstruos furiosos;

Sobre todo, debemos temer a su atrevido líder.

La tierra los soportó durante mucho tiempo con horror;

Y no se puede entregar la naturaleza demasiado pronto.

(3.2.926-929)

Frente a estos monstruos, el Dios de los judíos es un ser inmensamente poderoso, al cual se someten todos los elementos del mundo, monstruos incluidos:

Al sonido de su voz huye el mar, tiembla el cielo;

Él ve el entero conjunto del universo como si nada;

Y los débiles mortales, vanos juguetes de la muerte,

Están todos ante sus ojos como si nada fueran.

(1.3.225-228)

Incluso el acontecer, que a veces pudiera parecer favorable a los enemigos de los judíos, está por completo sometido a la soberanía de Dios. Los dioses falsos nada pueden, sus dones son aparentes: "Nuestros soberbios vencedores, insultando nuestras lágrimas, / atribuyen a sus dioses la alegría de sus armas” (1.4.261-262). Los judíos, sin embargo, tienen en sus quejas, en sus infortunios, su defensa: "Corderos débiles entregados a lobos furiosos, / Nuestros suspiros son nuestras únicas armas"

${ }_{4}^{4}$ Puede señalarse aquí que a las obras La reina Ester (1613) y Amán y Mardoqueo (¿1624?) del dramaturgo judío converso Felipe Godínez se las llamó "comedias bíblicas". 
(1.5.306-307). Y entonces, la pluma de Racine anota lo que podría llamarse la premonición de la Shoa. Los judíos claman al cielo, están prontos a ser exterminados en un solo día:

¡Qué carnicería por todos lados!

Los niños y los ancianos son sacrificados

al mismo tiempo, y la hermana y el hermano,

la hija y la madre y el hijo en los brazos de su padre.

¡Qué montón de cuerpos! ¡Cuántos miembros dispersos

Privados del entierro! ¡Buen señor!

Tus santos son pastos de tigres y leopardos.

(1.5.317-323)

Una y otra vez reaparece la idea de que la legalidad, la Halajá, que Dios ha entregado a los judíos, ha sido también una y otra vez transgredida. Así, los causahabientes deben pagar por las faltas de sus causantes: "Nuestros padres han pecado, nuestros padres ya no existen, / y nosotros cargamos con el castigo por sus delitos" (1.5.334-335). Pues Dios — que nunca es mencionado en la meguilá pero sí en la pieza de Racine- es un gran archivero. En sus archivos constan los activos y pasivos, y no hay deuda que no se pague. Es precisamente gracias al archivo, en este caso el del rey Asuero, que éste podrá enterarse de los méritos de Mardoqueo:

Finalmente, cansado de llamar a un sueño que huye

de él, para apartar de él estas imágenes fúnebres,

hizo que le trajeran estos famosos anales en los que se trazan

los hechos de su reinado, cuidadosamente recogidos,

por manos fieles cada día.

Guardamos por escrito servicio y ofensa,

Eternos monumentos de amor y venganza.

(2.1.392-398)

Amán, con todo, posee el don de la palabra. Su discurso parece más convincente que las crónicas que se le leen al rey. Le habla mal de los judíos y formula preguntas venenosas:

Los pinté poderosos, ricos, sediciosos,

Su dios incluso enemigo de todos los demás dioses.

"¿Hasta cuándo permitiremos que esta gente respire

y un culto profano infecte tu imperio? [...]"

(2.1.495-498) 
Ambos monstruos - Asuero y Amán - acuerdan el día en que se autorizará asesinar a todos los judíos que habitan las 127 provincias del Imperio Persa: "De la carnicería con él resolví el día”, dice Amán (2.1.510).

El poder del discurso en la corte es mortífero, en él el peso específico de cada palabra cuenta al cien por cien: “¿Y no puedes exterminarlo con una palabra?” le pregunta Hydaspe a Amán refiriéndose a Mardoqueo (2.1.515). El poder del discurso se compensa pero a veces se refuerza a consecuencia del carácter imprevisible de Asuero. Su poder se basa en eso: "Sabes cuán es terrible en sus repentinos transportes, / De nuestros designios a menudo rompe todos los resortes", Amán le explica a Hydaspe sobre el rey (2.1. 519-520). Según veremos, el poder del discurso logra en Ester un paralenguaje que seduce a Asuero.

El rey está inquieto por la fuga del pasado, por el desconocimiento del pasado. Presiente que su Imperio se desintegrará en la medida que él no conozca ese pasado: "Pero más rápido que un rayo, el pasado se nos escapa" (2.2.546); de ahí que esté "el mérito olvidado" (2.3.551).

La deferencia del rey por quienes le han rendido servicios explica su curiosidad por la identidad de una persona que ha señalado a unos conspiradores que planeaban atentar en contra suya: "Y menos debo olvidar la virtud, / que se olvida de sí misma. ¿Su nombre es, dices?", le pregunta Asuero a Asaf (2.3.563-564). Sin embargo, esta misma deferencia es la que lo expone a las manipulaciones de Amán, cuyo consejo, el rey dice, aligera sus deberes: "del cetro en mi mano ha aliviado el peso" (2.5.581), pues Asuero entiende que requiere "consejo sobre el vasto poder" (2.5.590).

Y mientras valora los méritos de los servicios prestados y el consejo, el rey también a veces rompe las reglas. Ester rompe la rígida regla y se acerca al rey sin esperar que él la llame con el ademán de su báculo. Como se trata de su acción más temeraria, aquella a partir de la cual sus planes se dan con facilidad, ella se desmaya. Cuando vuelve en sí le dice a Asuero: “¿Qué voz saludable manda que yo viva, / y que vuelva a mi seno mi alma fugitiva?" (2.7.641-642). Es la voz del poder la que la hace volver en sí. Ella lo teme como lo temería cualquier otro, al punto que tal vez se ha desmayado por el solo hecho de transgredir la regla: "En este trono sagrado, rodeado de relámpagos, / pensé verlos a todos listos para reducirme a polvo" (2.7.649-650). Asuero sabe que tiene que defender la majestad de su poder.

La soberanía de Ester sobre el corazón de Asuero es la de una belleza humilde y ética. El poder, que ve en ella deferencia, le devuelve el doble de deferencia. Pero, además, es una soberanía persuasiva la de Ester sobre la soberanía temible de Asuero. Esta "soberanía sobre su corazón” (2.7.664) significa además que aquella soberanía terrible posee un núcleo sensible sobre la que recae la influencia de la soberanía persuasiva. El mismísimo Asuero se hace capaz de verbalizar así sus sentimientos hacia Ester: En este segundo momento el monstruo deja ver que él no es cruel: 
Créeme, querida Ester, este cetro, este imperio, Y estos profundos respetos que inspira el terror,

Su pomposo brillo que mezcla poca dulzura, a menudo fatiga a su triste dueño.

Solo encuentro en ti no sé qué gracia

Que siempre me encanta y nunca me cansa.

¡De virtud amorosa, atractivos dulces y poderosos!

Todo en Esther respira inocencia y gozo.

\section{(2.7.665-672)}

Ester no está decidida a hablar, pero Asuero le insiste en que se abra. El monstruo le pide que se fíe de él: "Habla: de tus deseos el éxito es seguro, / si este éxito depende de una mano mortal" (2.7.683-684).

En esta segunda prueba de confianza - la primera fue la transgresión de la regla de audiencia - Ester sabe que da un paso en el vacío que se parece mucho a uno en falso: "Espero mi desgracia o mi felicidad; / Y todo depende, Señor, de tu voluntad" (2.7.687-688).

Mientras el monstruo humano pide confianza, el personaje que no aparece en la pieza, pero que sí al menos se lo menciona, sigue oculto, su única presencia es su ley inflexible:

¿Quién arroja sobre todo el universo una noche tan oscura?

Dios de Israel, finalmente disipa esta sombra:

¿Cuánto tiempo estarás escondido?

(2.8.747-749)

En paralelo, los dioses falsos parecen auspiciar los logros del Imperio que gobierna a 127 provincias, si es que no es porque "un ídolo silencioso" (2.8.760), "un dios sin fuerza y sin virtud" (2.8.764), en verdad nada más son demonios, no comparables con el Dios de los judíos:

Dioses impotentes, dioses sordos, todos los que te imploran nunca serán escuchados.

Que los demonios y sus seguidores

sean destruidos y confundidos para siempre.

(2.8.767-770)

Los judíos, que gracias a sus extensas genealogías conocían el rigor de los largos plazos, saben en Ester que la gloria de ningún Imperio es eterna, y que, pese a sus calamidades, finalmente triunfarán: "La gloria de los malvados en un momento se extingue. / La terrible tumba los devorará para siempre” (2.8.818-819). 
Como sea, si la realidad no calza con las promesas de Dios: "Hay contratiempos que el sabio debe borrar" (3.1.841) y no dejarse seducir con las promesas: "Solo para hacerme sentir mejor tu tiranía, / Y finalmente abrumarme con más ignominia” (3.1.886-887).

Mientras tanto, el desprecio a los judíos se acrecienta. Se los considera inferiores a los cuales someter:

¡Oh vergüenza, que nunca podrá borrarse!

¡Un judío execrable, oprobio de los hombres,

Se ha visto, pues, de púrpura vestido por mis manos!

Es poco que haya ganado la victoria sobre mí;

Infeliz, serví como heraldo de su gloria.

(3.1.845-849)

Las palabras de Amán arriba citadas han sufrido, sin embargo, otras interpretaciones. La rivalidad entre los ministros ha sido caracterizada por Mitchell Greenberg como una tensión homosexual que hace pasar a segundo plano la relación entre Asuero y Ester5.

Con todo, los judíos, por su parte, desconfiarán de la corte persa: "El mar más terrible y tormentoso / es más seguro para nosotros que esta corte engañosa" (3.1.904-905). Y es que el pueblo judío sabe leer, hecho que constituye una ventaja: "Podemos leer furia y rabia en sus ojos" (3.3.940), gracias a lo cual desconfía de quienes se debe desconfiar.

La imagen del monstruo antijudío es la de un tigre hambriento de sangre. La idea del tigre a la mesa del rey, consiguiendo sus favores y haciéndose necesario es, si se permite exagerar y fantasear, casi otra premonición, la de Arturo Ui, Hitler a la derecha de Paul von Hindenburg:

No sé si este tigre reconoció a su presa;

Pero mirándonos, hermanas mías, me pareció que

Tenía un gozo bárbaro en sus ojos,

cuya sangre todavía está turbada.

ELISE:

¡Cómo aumentará su atrevimiento este nuevo honor!

Lo veo, hermanas mías, lo veo:

en la mesa de Ester el insolente cerca del Rey

ya ha tomado su lugar.

(3.3.942-949)

\footnotetext{
${ }_{5}^{5}$ Explica Mitchell Greenberg: "Racine complica su trama al reemplazar el interés amoroso heterosexual por lo que solo puede denominarse una exacerbada rivalidad homosexual cuya intensidad presagia un desastre catastrófico (...)" (2010: 229).
} 
El amor es aquello que concuerda al poder con sus súbditos. Encuadrando la tesis según la cual conviene más al soberano hacerse temer que amar, Racine dice que aquel temor solamente es beneficioso si el rey es amado:

¡Qué feliz es el pueblo, cuando un rey generoso, temido en todo el universo, todavía quiere ser amado!

(3.3.960-962)

Como explicará Michel Foucault en su ciclo de conferencias La verdad y las formas jurídicas, en un momento el saber y el poder ya no coinciden en la misma persona. El saber y el poder van por cuerdas separadas. Los judíos dispersos en el Imperio Persa parecen saberlo - "Un rey sabio, enemigo del lenguaje mentiroso" (3.3.987) - , por eso necesitan que el poder tenga buenos consejeros, deben, de alguna manera, abrirse paso hasta el trono para garantizarse a ellos mismos una alianza duradera entre saber y poder:

¡Oh descanso! ¡Oh tranquilidad!

¡Oh de perfecta felicidad eterna seguridad, cuando la autoridad suprema en sus consejos tiene siempre con ella la justicia y la verdad!

(3.3.964-968)

Y agrega mediante la técnica de intervención paradójica una apología política de Luis XIV (o eso es lo que implica):

Admiro a un rey victorioso, que

su valor lleve triunfante en todos los lugares,

pero un rey sabio que odia la injusticia,

que bajo la ley de los ricos imperios

no deja que los pobres giman,

es el regalo más hermoso del cielo.

(3.3.989-994)

El monstruo no es siempre un monstruo por fuera, muchas veces sabe mostrarse por sobre el común, hacer el papel del mejor:

De este monstruo feroz

Teme la pretendida dulzura.

La venganza está en su corazón

y la misericordia en su boca.

(3.3.977-980) 
El rey cree que debe arrancar un secreto a Ester o es eso lo que le hace pensar ella. Él dice ver en ella "Una noble modestia en todo lo que hace" (3.4.1017) y es descrita por el rey Asuero como "la inocencia y la sabiduría misma" (3.4.1037). Además, se hace las preguntas y le hace las ofertas del enamorado:

¿Qué clima contenía un tesoro tan raro?

¿En qué vientre virtuoso has nacido?

¿Y qué mano tan sabia crio tu infancia?

Pero di rápidamente lo que preguntes:

Todos tus deseos, Ester, te serán concedidos.

Si lo dijiste y estuvieras dispuesta a decirlo de nuevo, pide la mitad de este poderoso imperio.

(3.4.1019-1025)

Es entonces cuando Ester lleva a cabo un acto imprevisto, que sería imposible en otra pieza de Racine: se arroja a los pies del rey, pero antes dice:

No me pierdo en estos vastos deseos.

Pero ya que finalmente debo explicar mis suspiros,

Ya que mi rey mismo me invita a hablar,

(Se arroja a los pies del Rey.)

Me atrevo a implorarle, y por mi propia vida,

Y por los tristes días del pueblo desdichado, condenaste a perecer conmigo.

(3.4.1026-1031)

El rey Asuero pregunta de qué está hablando y que cuál es ese pueblo (mientras levanta a Ester del suelo). Amán susurra que tiembla. Ester por fin habla en tercera persona: "Ester, Señor, tenía un judío como padre. / Conoces el rigor de tus malditas órdenes" (3.4.1032-1033).

Y Ester hace su gran apuesta. Le pide a Asuero solamente una cosa: que la escuche hasta el final, que le permita completar su discurso y, mientras tanto, que Amán, en quien ve el peligro más real, no la interrumpa:

Puedes rechazar mi súplica,

Pero te pido al menos que, coma última gracia, hasta el final, Señor, me oigas hablar, y sobre todo que Aman no se atreva a molestarme.

(3.4.1040-1043)

Entre los versos 1044 y 1088 de la tercera escena del tercer acto, Ester expone cuál es el dios de los judíos: 
El Señor es su nombre. El mundo es su obra;

Oye los suspiros de los humildes que son insultados,

Juzga a todos los mortales con leyes iguales,

Y desde su trono interroga a los reyes.

(3.4.1052-1055)

Como también la historia de este pueblo: "Los judíos se atrevieron a dirigirse a otros dioses" (3.4.1058). Le cuenta a Asuero sobre el triunfo de la invasión de los asirios y la posterior cautividad babilónica: "Bajo los asirios, su triste servidumbre / se convirtió en el justo precio por su ingratitud" (3.4.1060-1061). Y luego, la liberación gracias al rey Ciro:

Pero para finalmente castigar a nuestros amos,

Dios eligió a Ciro antes de que naciera,

lo llamó por su nombre, lo prometió a la tierra,

lo dio a luz y de repente lo armó con su trueno.

(3.4.1062-1065)

Sin embargo, predecesores de Asuero dejaron atrás los logros de Ciro:

Su hijo interrumpió el trabajo iniciado,

Estaba sordo a nuestros dolores. Dios rechazó su raza,

lo cortó y lo puso a usted en su lugar.

(3.4.1075-1077)

Así, Asuero aparece ante sí mismo como inscrito en los planes de la deidad de los judíos. Estos 44 versos son el centro asimétrico y la culminación de la obra, además de que el número 44 es importante para la cábala.

Es así como Ester denuncia a Amán "Un ministro hostil a tu propia gloria..." (3.4.1088) en tanto que vindica el comportamiento pacifista del pueblo judío:

Y qué reprocha a los judíos su odio envenenado?

¿Qué guerra territorial hemos comenzado?

¿Se les ha visto caminando entre tus enemigos?

¿Fueron cada vez más esclavos sumisos?

Adorando en sus grilletes al Dios que los castiga.

(3.4.1104-1108)

El mismo Dios ha hecho próspero al rey Asuero, su dominio territorial está dado por el control de la población y el de los mares: "Disipó ante ti a los incontables escitas / Y encerró los mares dentro de sus vastos límites" (3.4.1116-1117). Esta idea del imperium -el control de la población (que excluye o somete otras poblaciones) y el control de los mares (que los reduce a esas pozas de agua que llamamos lagos) - 
además de ser muy compatible con los afanes centralistas de Luis XIV, postula un doble sentido paradójico de la soberanía: por una parte el rey es enteramente soberano (domina el territorio) y por la otra su soberanía depende del verdadero soberano, por lo que un soberano eficaz solo lo es en la medida que es consciente de sus limitaciones, de sus dependencias, de las condiciones bajo las cuales opera. De ahí que el soberano pueda reconocer con estoicismo: "Entonces yo era el juguete..." (3.4.1138). Mientras no ha sabido que era juguete han estado jugando con él. Precisamente, quienes juegan con él han sido quienes lo han azuzado para que despliegue su poder, mientras que quienes lo han hecho hacerse consciente de la naturaleza de su poder son aquellos que le han enseñado sus límites en el cielo y en la tierra, Ester y Mardoqueo.

Pero la tarea de Ester no está completa mientras no defienda a Mardoqueo: “¡Pobre de mí! este judío una vez me adoptó como su hija” (3.4.1120). Ante eso, en un acceso de debido proceso, Asuero manda a llamar a Mardoqueo: "Llama a Mordecai, él también debe ser escuchado" (3.4.1140).

Llega el momento en que el monstruo Asuero pondrá bajo control al monstruo Amán. Ester se lo anuncia a su rival:

Vete, traidor, déjame.

Los judíos no esperan nada de un villano como tú.

Miserable, Dios vengador de la inocencia,

Listo para juzgarte, ya sostiene su balanza.

(3.5.1153-1157)

Aquí es cuando tiene lugar el célebre pasaje de Ester 7: 8 en el Tanaj que ha sido tan debatido por los rabinos. 6 Asuero, al ver que Amán se precipita sobre Ester, declara: "Deja que este monstruo sea instantáneamente arrancado" (3.6.1172).

Habiéndose desecho del mal consejero, el soberano cuenta ahora con una conciencia, eleva a Mardoqueo a la dignidad de primer ministro en tanto se deshace de sus anteriores consejeros. Asuero dice a Mardoqueo:

Amado mortal del cielo, mi salvación y mi gozo,

tu rey ya no es presa del consejo de los impíos.

Mis ojos están abiertos, el crimen es confuso.

Ven y brilla a mi lado en el rango que te corresponde.

(3.7.1179)

${ }^{6}$ Ester 7: 8 dice: "Después el rey volvió del huerto del palacio al aposento del banquete, y Amán había caído sobre el lecho en que estaba Ester. Entonces dijo el rey: ¿Querrás también violar a la reina en mi propia casa? Al proferir el rey esta palabra, le cubrieron el rostro a Amán". 
La muda de consejeros corresponde a un clásico de la intriga ministerial que dice que ver con esa difícil relación entre el poder y el saber. Al estar divididos el poder y el saber obedecen a una estructura de separación de poderes: el poder es un saber que - en el mejor de los casos- sabe que no sabe (y en el peor, no sabe que no sabe); el saber es un poder que - en el mejor de los casos- sabe que no puede (y en el peor, cree poder solamente porque sabe). Al complementarse, el poderoso ofrece al sabio lo que no puede y el sabio al poderoso lo que no sabe (si se cumple el mejor de los casos en ambos). Asuero y Mardoqueo hacen una dupla imbatible porque el rey se hace capaz de revocar, aunque no pueda, su voluntad previa, se doblega su poder ante lo que ahora sabe, no insiste en mantener erguido su poder a pesar de lo que ha llegado a saber. Proclama Asuero: "Si puedo oírte. Vayamos, por órdenes contrarias, / revocando las órdenes sanguinarias de los malvados" (3.8.1196-1197). En tanto, sus nuevos consejeros saben cómo justificarlo ante él y ante sí mismos: Y es que el rey no tenía cómo saber que era engañado:

Un corazón noble no puede sospechar en los demás

La bajeza y la malicia

Que no siente en sí mismo.

(3.9.1218-1220)

Como el derecho es una invención - para decirlo con Kant-universal y necesaria es también el lugar para "las trampas del artificio" (3.9.1217). La ley y la doctrina, el poder y el consejo, el derecho es eso. La doctrina aconseja al poder de la ley, la ley da poder a la doctrina. Algunos rabinos sostuvieron que Asuero era un tonto, y otros que no lo suficiente como para no mudar de consejero o haber perseverado en su error. Puede concluirse que la ley como el poder es menos tonta si oye el consejo de la doctrina. El problema: que más allá del oído está el corazón. El corazón, sin duda, ha sido fundamental para el feliz desenlace de este relato, en el Tanaj y la versión de Racine: “¿No tienes su oído y su corazón?” (3.2.915).

$\mathrm{El}$ amor necesita confiar y solamente es confiable la inocencia.

El coro podrá decir que Dios hace triunfar la inocencia: "Cantemos, celebremos su poder" (3.9.1200-1201), pero ¿es Ester tan inocente? El discurso de Ester posee una función terapéutica, la de calmar al rey, resolver sus dudas, aclarar el mundo: "como David, que con sus conmovedoras cuerdas, / calmó la salvaje tristeza de un rey celoso" (3.3.958-959).

La confesión de Ester al rey puede leerse en varios niveles. En un primer nivel, es la confesión de un secreto que significa un riesgo muy importante: ella no sabe cuál será la reacción del monarca. En un segundo nivel, es un presupuesto para abordar la defensa de Mardoqueo, es decir, de su tutor. En un tercero, para hacer la defensa de su pueblo. Ester se comporta como una verdadera abogada defensora, el despliegue de sus argumentos es de una sobriedad exquisita a la vez que contundente. Vemos 
cómo se deja caer a los pies del rey Asuero, para desde este lugar tan bajo comenzar a ascender otra vez. La defensa de su amor, de su relación conyugal pasa prácticamente desapercibida comparada con la de la de Mardoqueo. Esta es netamente política porque es la defensa de un consejero en contra de un primer ministro, o sea, Amán. Es una jugada peligrosa. Después, la defensa del pueblo judío es maravillosa porque se enmarca en un relato histórico. Ese relato es la historia reciente del pueblo judío, la de su cautividad babilónica y el papel que en su liberación desempeñará el rey Ciro II de Persia (circa 600/575-530 a. C.). Es a partir de Ciro cuando la historia del rey y la de Ester se conectan, antes de que ellos siquiera se hayan conocido e incluso nacido. Ester le hace recordar al rey Asuero la vieja amistad entre su pueblo judío y el Imperio Persa. El rey parece haberse olvidado, Ester es una cronista.

El monstruo es arrancado del alma. Lo que hace Ester es aclarar quién es cada uno, disolver la nebulosa confusión que ha creado Amán, devolver al poder la lucidez que es no otra cosa que su historia. Pero además, y esto tal vez sea lo más notable, Ester al reconocerse como judía, a la vez que ha corrido un riesgo frente al rey - "Y la muerte es el precio de todo atrevido / que, sin ser llamado, se presenta a tus ojos" (1.2.195-196)—, también se ha dejado capturar por la ley de Moisés. La Mitzva, cuyo riguroso cumplimiento es lo que distingue a los judíos al interior del Imperio Persa, atañe a la reina, ella está bajo esa ley particular propia de súbditos. Se lo recuerda Mardoqueo cuando Ester parece no convencida de arriesgarse:

Piénsalo bien: este Dios no te ha elegido

para ser un vano espectáculo a los pueblos de Asia,

ni para encantar los ojos de los gentiles.

Para un uso más noble reserva a sus santos.

(1.3.213-216)

Ester deja claro que ella está bajo la ley. A diferencia de Herodías, que en el evangelio de Mateo pide la cabeza de Juan "el bautista" (Mt. 14: 1-7), Ester le devuelve la cabeza a Mardoqueo pero también a todos los judíos. Y al hacerlo, ella deja vivos a todos sus jueces, a todos sus acusadores, a todos los esclavos de la ley - porque ella se sabe conviviendo entre ídolos: "Todo su palacio está lleno de sus imágenes" (2.8.74)—, esos que desde ahora observarán y juzgarán su comportamiento.

Ester no impone su dios al rey Asuero, pero le deja bien claro que su dios es muy poderoso y castigador. De esta manera, Ester aparece precaviendo al rey de cometer una falta ante poderes que son aún más altos que los suyos. Esta astucia que podría considerarse otro desacato, y que podría haber significado la ira del rey, suma a favor de Ester. De ahí que los buenos oficios de Ester recompongan el equilibrio de fuerzas en el imperio. El rey seguirá adorando a sus dioses y los judíos al suyo. Ester continuará siendo la reina y su tutor, ahora estará más cerca de ella. Lo que sigue es un ajuste de cuenta en el que los judíos matan a quienes se habían preparado 
visiblemente para matarlos a ellos. Sin embargo, no los despojan de sus patrimonios. No hay botines al interior del imperio ni para su ley.

Pero, para nuestros efectos, no es tan importante Ester ni Mardoqueo como el rey Asuero. Este rey consigue practicar algo así como el principio de deferencia. Sabe que olvida, por eso pide que le recuerden, recibe consejos, toma decisiones, se equivoca, echa pie atrás, revisa, corrige. El monstruo que late en el rey Asuero, que tanto Ester como los judíos perciben con terror, está gobernado, encadenado, no es un monstro como Amán, que tiene hambre y debe comer a toda costa. Podría decirse que el monstruo está sometido al amor, pero decir eso significa admitir que toda soberanía confiable es una soberanía sometida, una que está de alguna manera concordada con otras. Ni el rey Asuero, que impera sobre 127 provincias, es plenamente soberano y es precisamente por eso que llega a ser juicioso aun cuando no lo haya sido siempre.

\section{5}

En la sección titulada "Esther y la fragilidad de la memoria", de Nicholas Hammond, y en Jean Racine: Life and Legend, de John Sayer, ambos autores recuerdan que tempranamente Madame de Maintenon fue considerada, al menos en los círculos de Port-Royal, una segunda Esther, analogía sugerida por el Conde Brienne (1594-1666) en sus Memorias (Sayer, 2006: 338 y Hammond, 2004: 157), en donde postula que Luis XIV: "Conoció a una segunda Ester, quien lo salvó del naufragio. Es digna, esta Ester, de toda alabanza", para a continuación compararla con Santa Clotilde que salvó al rey Clovis de la idolatría (Loménie, 1828: 248).

Es posible que los judíos hayan sido aquí los calvinistas y Ester, Madame de Maintenon, que, como ella, fue la segunda mujer del rey y había pertenecido a la secta minoritaria. Racine sería el Mardoqueo de Madame de Maintenon, porque le recuerda quién es y cuál es su tarea.

Mientras el Asuero de Racine parece el custodio de la minoría a manos de la mayoría, con el Edicto de Fontainebleau Luis XIV revocará el edicto de Nantes (1598), en 1685, cuatro años antes del estreno de Ester. Los años desde 1685 a 1689 coinciden con el silencio de Jean Racine. Cuando por fin el poeta cortesano abre la boca el edicto revocatorio sigue vigente y lo seguirá estando. Enrique IV de Navarra, de quien Luis XIV había heredado su calidad de rey de Navarra, había sido el responsable del edicto que proclamó la tolerancia. No deja de ser curioso que entre Ciro II de Persia, que liberó a los judíos, y Jerjes, que se supone fue el Asuero, están Darío y otros, tal como entre el tolerante Enrique IV de Navarra y el intolerante Luis XIV estuvo Luis XIII, quien, pese a todo, no revocó el edicto legado por su antecesor. De ahí que las preguntas que laten en la Ester de Racine son: si Asuero restauró la tolerancia a los judíos que le había legado Ciro ¿por qué tú, Luis, no has podido, no restaurar, sino 
nada más que mantener la tolerancia que Enrique IV legó a Luis XIII y Luis XIII te legó a ti? Y a Madame de Maintenon: si eres la segunda ¿te harás la primera como Ester o te quedarás erguida y muda? El reputado tonto Asuero supo enmendar su primera falta, ¿cómo Luis, tanto más inteligente, no sabrá enmendar la suya? Si Mardoqueo domesticó al monstruo a través de una mujer — se dice Racine-, ¿será capaz de lo mismo a través de otra mujer? ¿Restaurará la poesía al derecho? ¿0 es que acaso solo otro monstruo podrá salvarnos?

Finalmente, ¿qué rol ocupó en esta intriga palaciega el propio Jean Racine? ¿Se veía así mismo como un Mardoqueo, en este caso, un Mardoqueo que redactaba los diálogos del poder? Los críticos del monstruo no entienden que el monstruo siempre se las arregla para existir. A diferencia del poeta maldito, su antónimo, el poeta cortesano, no tiene la intención de aniquilar al monstruo o serlo él mismo -asume que surgirá otro peor- como más bien de domesticarlo. La literatura romántica abusó de la ridiculización del poeta cortesano. En el Evgueni Onieguin, de Aleksandr Pushkin, por ejemplo, uno de esos, francés de exportación, el "socarrón messie Triquet [...] / auténtico francés" (5, XXVII) aparece reducido a una triste función zalamera, la de celebrar a doncellas que se presentan en sociedad, cantándole a Tatiana con un papelito en la mano.

Pero antes de caer tan bajo, el poeta cortesano tuvo la vocación de darle al poder no solamente una mejor apariencia, sino que también la de instruirlo, hacer al monstruo menos monstruoso. Eso que a partir de las revoluciones de los siglos XVIII y XIX pretendió lograr el derecho constitucional - -0 , si se prefiere, el constitucionalismo - concibiendo nuevos monstruos para que supuestamente pudieran contrapesarse entre sí.

\section{Bibliografía}

Barthes, R. (1996): Sobre Racine. Ciudad de México, Siglo XXI.

Bello, A. (1981-1987): "Compendio de la historia de la literatura", en Obras Completas, tomo 9. Caracas, La Casa de Bello.

Brecht, B. (2008): “La evitable ascensión de Arturo Ui”, en Teatro completo, vol. 9. Madrid, Alianza.

Brecht, B. (1996): “Terror y Miseria del Tercer Reich”, en Teatro Completo. Madrid, Alianza.

Chiarini, P. (1994): Bertolt Brecht. Barcelona, Nexos. 
Curcó Cobos, F. (2013): "La polémica Kelsen-Schmitt: un debate jurídico en torno a la Modernidad", Diánoia, 58 (71).

Eurípides (1990): “Hipólito”, en Tragedias, vol. I. Madrid, Gredos.

Eurípides (1990): “Los Heráclidas”, en Tragedias, vol. I. Madrid, Gredos.

Foucault, M. (1996): La verdad y las formas jurídicas. Barcelona, Gedisa.

Greenberg, M. (2010): Racine: From Ancient Myth to Tragic Modernity. Minneapolis, University of Minnesota Press.

Hammond, N. (2004): Fragmentary Voices: Memory and Education at Port-Royal. Tübingen, Gunter Narr Verlag.

Hirsch, E. G., J. Dyneley Prince y S. Schechter (1901-1906): "Esther”, artículo en Jewish Encyclopedia, The unedited full-text of the 1906 Jewish Encyclopedia. Version online de la obra en 17 volúmenes publicada originalmente entre 1901-1906. Disponible en https://www.jewishencyclopedia.com. [Consulta: 15 de septiembre de 2021].

Ibsen, H. (2000): Casa de muñecas. Buenos Aires, Losada.

Lemosín Martal, R. (1983): El libro de Ester y el Irán antiguo: estudio filológico-derásico de vocablos arameoelamitas persas. Madrid, CSIC.

Loménie, H. A. de (Conde de Brienne) (1828): Mémoires inédits de Louis-Henri de Loménie, comte de Brienne, secrétaire d'État sous Louis 14.; publiés sur les manuscrits autographes, avec un essai sur les moeurs et sur les usages du 17. Siécle. Paris, Ponthieu et Cie., Libraires, Palais-Royal.

Neumann, F. (1943): Behemoth. Ciudad de México, FCE.

Padoan, G. (1970): "Fedra", en Enciclopedia Dantesque. Roma, Istituto della Enciclopedia italiana. Disponible en https://www.treccani.it/enciclopedia/fedra [Consulta: 15 de septiembre de 2021].

Pushkin, A. (2013): Evgueni Onieguin. Buenos Aires, Colihue.

Racine, J. B. (1952): "Phèdre", en OEuvres complètes. Paris, Gallimard, Bibliothèque de la Pléiade. 
Racine, J. B. (2005): Esther: tragédie en trois actes. Boston/New York/Chicago, D. C. Heath \& Co., Publishers.

Rousseau, J. J. (1985): Emilio o De la educación. Madrid, Edaf.

Sayer, J. (2006): Jean Racine: Life and Legend. Peter Lang.

Séneca, L. A: (2001): "Fedra”, en Tragedias. Madrid, Gredos.

Shapiro, S. L. (2013): “Autoridad”, Revista Derecho del Estado, 31, 5-77.

Steiner, G. (1970): La muerte de la tragedia. Caracas, Monte Ávila.

Trujillo, J. (2022): El dios de la máquina. Santiago, Roneo.

Weitz, E. D. (2019): La Alemania de Weimar: presagio y tragedia. Madrid, Turner.

Fecha de recepción: 21 de julio de 2021

Fecha de aceptación: 25 de septiembre de 2021 